\title{
37
}

\section{KNOWLEDGE BASED VIRTUAL COMMUNITIES FOR MOBILE AND COLLABORATIVE WORK IN EUROPEAN VEHICLE REPAIR NETWORKS}

\author{
André Quadt, Heiko Dirlenbach, Amit Garg, \\ Martin Weidemann, Volker Stich \\ Research Institute for Operations Management \\ at Aachen University of Technology \\ Pontdriesch 14/16 \\ D-52062 Aachen, GERMANY
}

\begin{abstract}
The automotive market - as from the economic perspective one of the most important European markets - is currently experiencing the impact of new legal regulations from the new "block exemption". Car manufacturers have to share repair and diagnostic information with the market participants of the European automotive aftermarket. Hence, new collaborative networked organizations and new business models are required, which will be supported by innovative applications and devices. MYCAREVENT is a European research initiative consisting of leading industrial partners of the automotive sector, and researchers focused on service development, process and organization management, e-Business, communication networks, as well as artificial intelligence and human-computer-interaction. These partners will generate new business models which will provide innovative services to the customer in a post "block exemption" era.
\end{abstract}

\section{INTRODUCTION}

The automotive service, maintenance and repair sector in Europe features a total volume of around 40 billion Euros. The large number of 210 million vehicle owners spends an average of 400 Euros per year and approximately 5000 Euros per average life of the vehicle on its repair and maintenance. The major service providers in this sector include the franchised dealers and independent repair shops. In addition the strong fleet of 18,000 roadside rescue service vehicles are sent on over 14 million missions per year. This highly knowledge and labour intensive sector is currently constrained by the restricted access to repair manuals and training for the independent service providers. This situation has been made possible, because certain market sectors, including the automotive markets, were protected from competitive regulations by the so-called "block emption". In wake of the new developments in the "block exemption", each market participant, including 
independent service providers, has the basic right to access all kinds of repair information, training material and tools, which are till date held exclusively by the vehicle manufacturers. Consequently, these new regulations provide the basis for increasing cooperation in this large sector and bears substantial business opportunities for all the participating members.

The core strategy of MYCAREVENT is to enrich the different service providers with access to currently restricted knowledge and tools in a truly mobile working environment. Empowering these service providers with enriched applications for knowledge management and smart devices will make them more flexible and competent. At the same time, the consumer will have access to world-class services with unmatched transparency and efficiency. To achieve this objective, a comprehensive business model is required, defining use cases, business relationships between partners and market strategies (including pricing models).

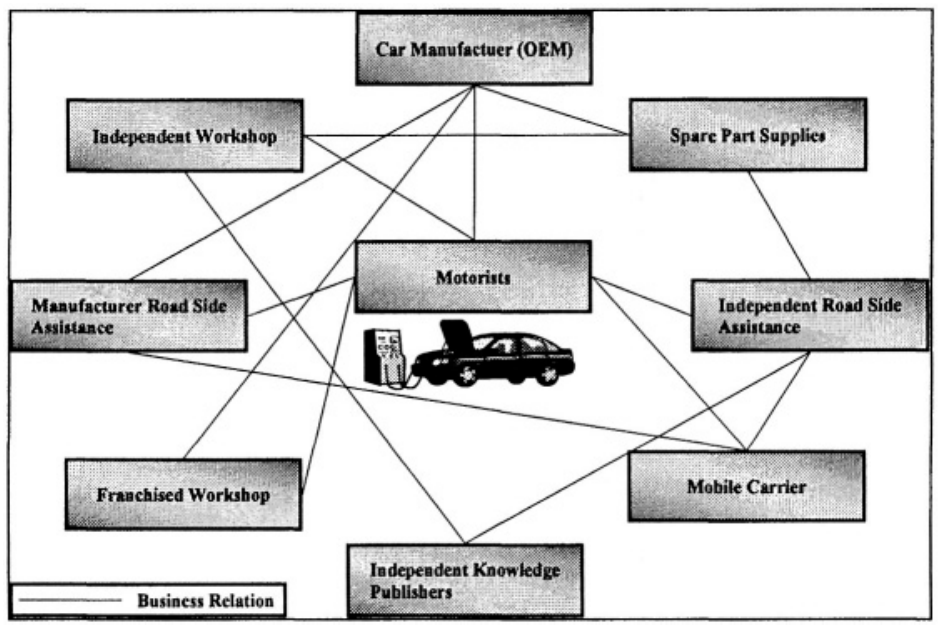

Figure 1: Collaborative networks in the automotive aftermarket consist of numerous partner with diverse roles

One of the critical issues to enabled that business model is to ensure easy and natural access to the various information, applications and services distributed among the network partners anywhere and anytime. This requires an "always connected" low cost communication network to facilitate communication between the mobile users and worker in a collaborative work environment. Moreover, the exchange of data among various partners has to be bases on a common standard to cooperate easily and efficiently. Innovative business models are essential to facilitate collaboration among the partners of a collaborative networked organization (CNO). Different aspects in the field of pricing strategy (e.g. flat fees, pay per use), financing issues and partner framework have to be discussed. In order to exploit the business potentials, a breeding environment to easily form and dissolve CNOs has to be established. One essential step towards this is to ensure interoperability between partners through flexible data standardization (partial standardization; mandatory \& variable parts). These standards need to be based on a powerful ontology.

The MYCAREVENT consortium aims to develop innovative applications and services that can be seamlessly and securely accessed and provided anywhere, 
anytime and in any context. It aims to set high standards in enabling and managing interactions between various partners. Context based, self-configuring smart applications will be the interface for the end users to easily access knowledge being provided and generated by the various partners. The interfaces will provide users with service options based on the context and location.

\section{COLLABORATIVE NETWORKED ORGANIZATIONS IN THE EUROPEAN AFTERMARKET}

The European Aftermarket consists of numerous and very heterogeneous types of participants, who operate in a highly competitive and dynamic environment. Initiated by the new block exemption regulations, new ways of integration and collaboration have to be sought, in order to fulfil the legal requests. Therefore, a process of integration among the diverse stakeholders has to be set up, which will foster collaboration rather than just cooperation. Collaboration is understood as guaranteeing a win-win situation for all participants through the fulfilment of common goals (see e.g. JARILLO, 1988). The MYCAREVENT project aims therefore to fully support all stakeholders in the European aftermarket in the conflicting fields of integration and competition by providing appropriate means.

In order to achieve the envisaged win-win situation, several pre-conditions have to be met:

- Overcoming of information asymmetry, especially between original equipment manufacturers (OEMs) and independents (see e.g. EISENHARDT, 1989)

- Guarantee of intellectual property rights and adequate compensation for knowledge providers (see e.g. HART, MOORE 1990)

- Seamless interoperability between the core information and communication systems of each partner

- Sharing of technical and financial risks (see e.g. RING, VAN DE VEN, 1992)

- Exploitation of business opportunities.

The solution to these challenges requires a multi-dimensional integrative approach. The dimensions featured by the MYCAREVENT initiative are on the level of business processes, information and communication technologies (ICT) as well as human-computer interaction.

A crucial point for the success of CNOs is the acceptance of the users. Users hereby means anyone who is supposed to use the services and processes provided by the networked organization including workshop mechanics as well as car drivers. These are one of the main focuses of MYCAREVENT's research efforts. Accordingly, different focus areas have been identified to cover the unique requirements of each user group. 


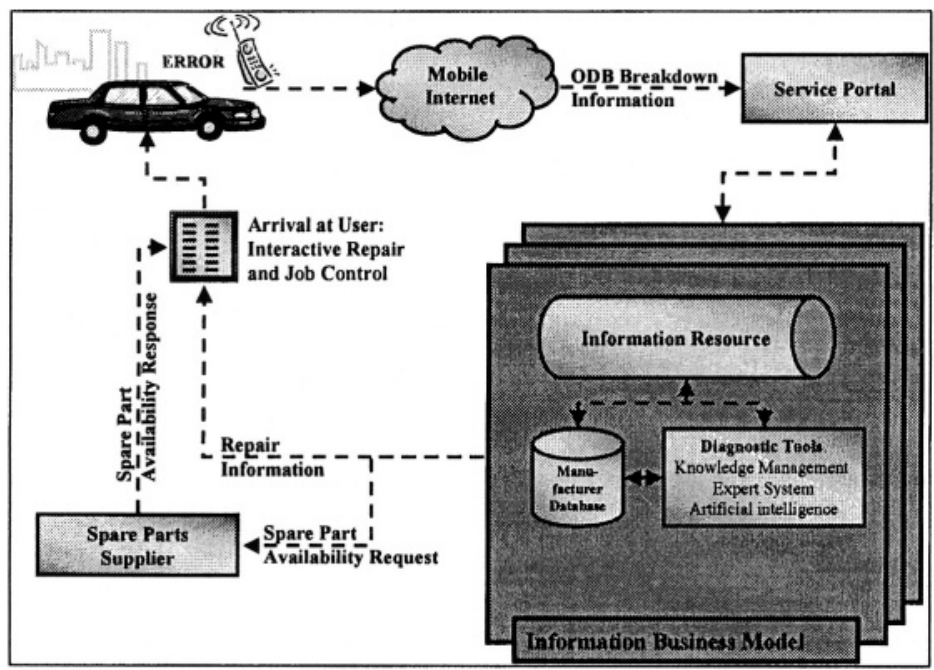

Figure 2: Example of a repair scenario involving independent road side assistance and spare part suppliers

Repair situations occur in different contexts. The MYCAREVENT consortium identified five repair and maintenance scenarios based on the different users for the repair services:

1. minor maintenance demands requiring driver self-help and clean-hand fixed (driver self-services)

2. break down situations involving independent service providers (manufacturer independent road assistance)

3. break down situations involving maintenance infrastructures of the OEM (manufacturer specific road assistance)

4. diagnose and repair services conducted by independent workshops (manufacturer independent workshops)

5. diagnose and repair services involving franchised dealers and workshops (manufacturer specific workshops)

As an example, figure 2 shows the situation of a car break-down on the road as considered by MYCAREVENT. The onboard diagnostic device transmits all information about the failure via a mobile data connection to the service portal of a road side assistance service. The appropriate portal is selected in respect to financial and personal preferences of the car driver (e.g. membership to motor club). The transmission of such data requires a standardized information interchange format, so that the service portal can communicate with any car, independently of make and model. The portal consequently accesses some information resource in order to obtain the required repair information. The providers of the accessed knowledge are compensated by some "Information Business Model". Afterwards, a road side technician is provided with the necessary repair information via his mobile device and sent to the break down site. At the same time, the required spare parts are identified. If the required parts are not onboard the service vehicle, the technician is informed, where he can pick up the necessary equipment. Having arrived at the break down site, the technicians has all the parts and information he needs to conduct a quick repair. Thus, the break down time can be minimized effectively. 
As can be seen from figure 2, communication and information between different partners play a crucial role in the MYCAREVENT environment. Therefore, key efforts are put into the integration of various mobile devices along with the on board diagnostic systems (OBD devices) and the fixed line communication infrastructure. Mobile devices will be equipped with a high level intelligence to enable communication of information, selection of services, specify customer preferences and carry out financial / accounting transactions. Developing common interfaces for enabling communication in all possible scenarios using smart devices will ensure user acceptance of the devices and business processes relying on them.

When different partners cooperate to provide enhanced services, it is essential that the roles and responsibilities of various members are unique and precisely defined. This will help to streamline the process of managing the car repair services. Hence, from an organizational perspective, the key requirements to provide enhanced value added services have also to be identified. To tackle this challenge, the MYCAREVENT initiative will apply state of the art methodologies as described in (Camarinha-Matos, 2003).

The basis for such collaborative networks as in the automotive aftermarket consists of an integration of processes among the diverse stakeholders, which will foster collaboration rather than just cooperation. MYCAREVENT aims therefore to fully support all stakeholders in the European Aftermarket in the conflicting fields of integration and competition by providing appropriate means to manage this conflict. A major benefit will be realized by providing an open service environment as well as streamlining and integrating adjacent processes for the whole value-chain of the European aftermarket via the service portals. In order to create a true win-win situation, the share of benefits among the partners has to carefully designed. The according business models therefore have to be designed in a holistic way. They incorporate not only a pricing model, but also sub models for competition strategies, partner networks, service provision processes, quality requirements, financing and investment strategies as well as risk prevention strategies.

\section{BUSINESS MODELS FOR CNO IN THE EUROPEAN AFTERMARKET}

The design of new business models for collaborative networked organizations, which are feasible and sustainable in an environment with changed legal regulations is a challenging task. In order to grasp the core tasks of a collaborative network organization, a systematic approach has to be used, in order to guarantee innovative business models in the European aftermarket. Current aftermarket service business models have not yet begun to address the specific issues that arise from the tensions and complexities inherent in the European as well as the global services in the automotive aftermarket.

Examining the term of "Business Model", a wide variety of definitions exist for business models (see, e.g. AFUAH, TUCCI, 2001; PORTER 2001; OSTERWALDER, PIGNEUR, 2002). On a very generic level, business models describe activity and information flows, in order to detect benefits of various business participants, such as customers, investors or debtors. From a holistic point of view, business models describe organizational and operational organizations on a 
very aggregated level which allow for target- and customer-oriented action (see also LAING, FORZI 2001). Business models should therefore take the (virtual) enterprises strategy into explicit account, in order to guarantee a sustainable success. The "House of Value Creation" (HoV) is a methodical approach, which structures and describes all business elements in partial models and thus allow for detailed economic partial analysis of companies and collaborative networks (LAING, FORZI 2001). As shown in figure 3, the partial models are all building upon the overall strategy.

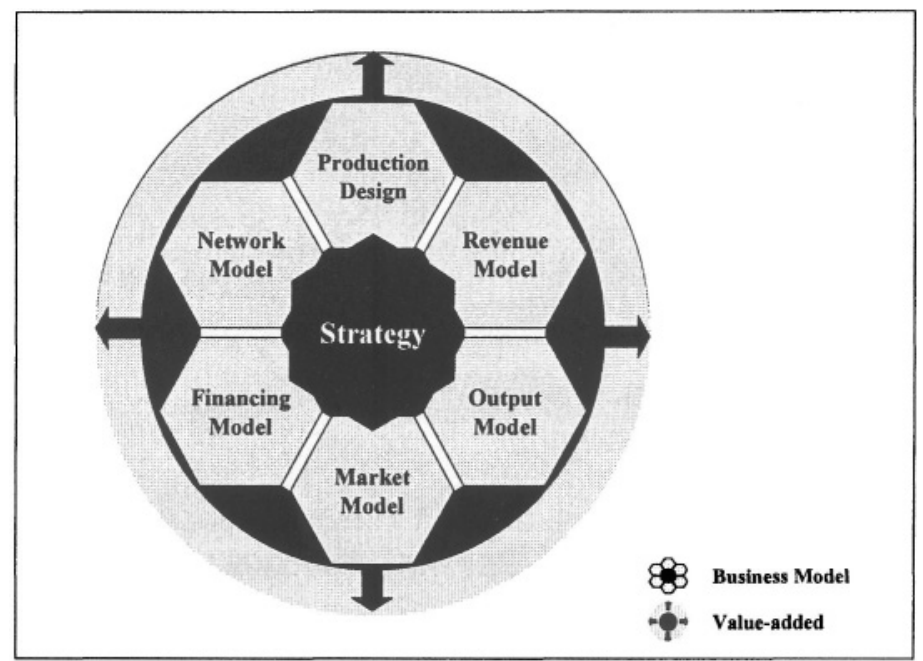

Figure 3: Strategy, business model and value added (LAING, FORZI 2001)

The analysis of the market model focuses on the identification and specification of products and services with regards to competitive and customer structures. In the case of the European aftermarket, new ways of collaboration among the various participants with varying degrees of competitive relations have to be identified.

The customer-orientation of MYCAREVENT will be guaranteed in the definition and design of outputs. Methods such as the Quality function deployment (PFEIFFER 1993; AKAO 1990) will be used in order to derive a benefit maximization for the recipient users.

Within the revenue model the pricing strategy will be derived. Considering pricing, the main focus should rather be put on the strategic position in the market than a cost-orientation, in order to guarantee maximized revenues. Companies tend to calculate their costs for certain products and services and then add a certain percentage of these costs as their revenue. For knowledge intensive services, however, these calculations do usually not work because knowledge can be multiplied at almost no costs (see below).

The partial model dealing with the production design is used to derive a detailed description of processes and performances inherent to the production of products and services.

In order to guarantee an effective and efficient collaborative network model and building upon the requirements on performances, the capabilities (including core competencies and capacities) of each participating partner will be scanned. The results will be used to have a detailed insight in how performances will be conducted 
by whom. Thus, a specific instantiation of the value chain and network configuration as well as an information model will be derived.

Taking into account the risks involved in such an investment intensive market, a thorough financing and risk analysis will be conducted within the financial model. Therefore, using suitable scenario techniques, the risks and chances will be calculated.

The method of the "House of Value Creation" is an iterative approach, which allows for adjustment of results conducted in previous steps. This approach should be followed as long as contradicting or competitive issues exist.

In order to represent the complex business structure of the automotive aftermarket a composition/decomposition derivate of the House of Value creation approach is required in order to enable each partner of the $\mathrm{CNO}$ to plan his business on his own while keeping the overall business structure in mind.

The pricing strategy for each network partner is of special relevance to this market sector. Although there are a number of business relations between various partner (see figure 2), the pricing between the motorist, the technician conducting the repair and the OEM as knowledge provider bears the largest challenges. This is due to the fact, that these business relations are the most subject to change in wake of the new block exemption regulations.

As a matter of fact, the motorist eventually has to pay for services which are linked to his car. For automobile clubs, he usually pays an insurance fee, i.e. a certain yearly amount independently of the occurrence of any incidents. This fits rather well with current business scenarios of the automobile clubs which maintain a certain infrastructure and self published (limited) information manuals. The costs for this infrastructure is as well rather independent from the number of actual incidents. This strategy, however, does no longer fit well, if in the field online information access considered. This online information access can provide comprehensive knowledge directly from the manufacturer. Knowledge providers, however, prefer pay-per-use models. Looking at the repair information portals of European OEMs, there are currently two different strategies. The pay-per-document strategy enables the download of a single document for a single user for a one-time fee. The document can then be accessed as many times as required without extra costs. The pay-per-page-impression model charges a fee for every access of a document independently of whether is has been accessed by the same user before.

In both cases, the costs of a repair are no longer independent from the number of incidents but rather correlated. Hence, the repairers business models have to be adopted. As the number of in-the-fleld repairs with increase and the breakdown time will decrease considerably, the motorists are expected to be willing to pay an extra premium. Whether this, plus the gains in efficiency will make up for the extra costs is currently subject to research.

\section{OUTLOOK AND CONCLUSIONS}

In order to define the business opportunities and the current business processes, a customer and stakeholder survey is conducted by MYCAREVENT amongst car drivers, roadside service personnel and garage mechanics. Independent service providers and the automobile manufacturers assist primarily in carrying out this survey. 
To strengthen the findings, detailed workshops and interviews with various stake holders and experts will be additionally conducted. Focus will be on capturing the customer's expectation from such innovative services and solutions. The goal of these workshops and interviews will be two-fold: first to assess their clarity of customer requirements in breakdown services and also to briefly identify their requirements for innovative services. System analysis methodology (using UEML Business Modeling; see e.g. CHEN et al. 2002) will be used for analysis and documentation of use cases generated based on customer requirements. These problems are then mapped to the potentials for new valued added services via a Opportunities/Potential Matrix Analysis (LUCZAK et. al., 2003) in order to derive lucrative business opportunities. The aftermarket of the European automotive sector bears substantial business opportunities. The introduction of innovative mobile applications will enable new ways of working and collaboration between car manufacturers, franchised and independent workshops and road assistance services as well as spare part suppliers and motorists. These opportunities are fostered by the new EC block exemption regulations which obligates the OEMs to provide the market with any information required for repair and maintenance tasks. However, these networks require carefully designed business models to generate win-win situation for all participants. The MYCAREVENT initiative will provide the necessary tools and build up best practices as a benchmark for further activities.

\section{REFERENCES}

1. Afuah, A.; Tucci, C.L. Internet Business Models and Strategies: Text and Cases. McGraw-Hill/Irwin, New York 2001.

2. Akao, Y. Quality Function Deployment: Integrating Customer Requirements into Product Design. Productivity Press, Portland, Oregon, 1990.

3. Camarinha-Matos, L. (Ed.). Collaborative Business Ecosystems and Virtual Enterprises. Kluwer Publisher 2003

4. Chen, D.; Vallespir B., et al. Developing an Unified Enterprise Modelling Language (UEML) Requirements and Roadmap. Collaborative Business Ecosystems and Virtual Enterprises. Camarinha-Matos, L. Kluwer Publisher: 2002; 247-254.

5. Eisenhardt, K.. Agency Theory: An Assessment and Review. Academy of Management Review, 1989. 14(1): p. 57-74.

6. Hart, O. and J. Moore. Property Rights and the Nature of the Firm. Journal of Political Economy, 1990. 98(6): 1119-1157.

7. Jarillo, C. On Strategic Networks. Strategic Management Journal, 1988. 9: p. 31-41.

8. Laing P.; Forzi T. E-Business and Entrepreneurial Cooperation. In: Proceedings of the 1st International Conference on Electronic Business (ICEB 2001), Hong Kong, December 19-21, 2001, S. 7-9.

9. Luczak, H.; Bleck, S.; Quadt, A. Electronic business engineering - exploiting the potentials of a wireless world. International Journal of Internet and Enterprise Management. Inderscience 2003 (1);31-52

10. Pfeiffer, T.: Qualitätsmanagement: Strategien, Methoden, Techniken. Munich: Hanser Verlag1993.

11. Porter, M.E.: Strategy and the Internet. Harvard Business Review, 79 (2001)3, S. 63-68.

12. Osterwalder, A.; Pigneur, Y. An e-Business Model Ontology for Modeling e-Business. In: Proceedings of the 15th Electronic Commerce Conference "e-Reality: Constructing the e-Economy, Bled (SLO), 17-19 Juni 2002.

13. Ring, P.S. and A.H. Van de Ven, Structuring Cooperative Relationships Between Organizations. Strategic Management Journal, 1992. 13: p. 483-498.

14. Society of Automotive Engineers (SAE). http://store.sae.org/overview.pdf

15. Ward, Benjamin. What's Wrong with Economics. New York: Basic Books, 1972. 